\title{
EDUCAÇÃO A DISTÂNCIA E A FORMAÇÃO EM SAÚDE: NEM TANTO, NEM TÃO POUCO
}

DISTANCE EDUCATION AND TRAINING IN THE AREA OF HEALTH: NOT SO MUCH, NOT SO LITTLE

Milta Neide Freire Barron Torrez ${ }^{1}$

Resumo O texto discute o papel da educação a distância (EaD) na formação dos profissionais de saúde, com vistas à democratização das oportunidades no contexto das estratégias que visam à consolidação do Sistema Único de Saúde (SUS). Partindo da experiência do Curso de Formação Pedagógica em Educação Profissional na Área de Saúde: Enfermagem (executado pela Escola Nacional de Saúde Pública Sergio Arouca, Fiocruz, e promovido pela Secretaria de Gestão do Trabalho e da Educação na Saúde, Ministério da Saúde), o texto apresenta estratégias capazes de, nesta modalidade, mediar propostas pedagógicas comprometidas com políticas públicas que buscam corresponder às demandas da educação em saúde como direito social. Constatando a necessidade de ampliação da oferta de projetos desta natureza no campo da saúde e reconhecendo os temores dos docentes e alunos em face do 'canto das sereias eletrônicas' e dos riscos de aligeiramento e descolamento político de formações promovidas nesta modalidade, reitera-se a crença de que a EaD é, antes de mais nada, educação. Palavras chave educação a distância; formação em saúde; formação de formadores; política pública.
Abstract This paper discusses the role distance education plays in the training of health professionals, in particular with regard to the democratization of opportunities, in the context of the strategies for the consolidation of the Brazilian Health System (SUS). Grounded on the experience of the Course of Pedagogical Training in Professional Education in the Area of Health: Nursing (run by the Secretariat of Health Work and Education Management of the Ministry of Health), the text presents strategies that, in this modality, are able to introduce pedagogical proposals related to the kind of public policies that, regarding education in the area of health as a social right, attempt to respond to the demands for this type of education. Verifying the need for more projects of this nature in the field of health, and being aware of the fears both teachers and pupils have of the 'electronic sirens' singing' and of the risk that this type of training may become too superficial or too detached from reality, we reaffirm our belief that distance education is, more than anything else, genuine education.

Key words distance education; training in the area of health; teachers' training; public policies. 
"Sólo le pido a Dios,

Que el dolor no me sea indiferente (...) Que el injusto no me sea indiferente (...)

Que el futuro no me sea indiferente Desahuciado 2 está el que tiene que marchar A vivir una cultura diferente" León Gieco e Mercedes Sosa

\section{Das escolhas que fizemos, o que esperamos}

Diante da possibilidade de ampliação do debate sobre educação a distância (EaD) e formação na área de saúde proporcionada por este contato com os leitores e debatedores convidados, interessados nas relações entre trabalho, educação e saúde e suas implicações nos processos de formação dos trabalhadores, identificamos, no presente texto, uma oportunidade de uma franca e generosa conversa coletiva.

Consideramos, como o 'chão' necessário para situarmos a nossa abordagem do tema, as aproximações proporcionadas pela implantação do Curso de Formação Pedagógica em Educação Profissional na Área de Saúde: Enfermagem (promovido pela Escola Nacional de Saúde Pública Sergio Arouca Ensp, Fiocruz, e executado pela Secretaria de Gestão do Trabalho e da Educação na Saúde, Ministério da Saúde), uma especialização pioneira, voltada para a formação de formadores que atuam no campo da educação profissional de nível técnico em saúde. O texto não será um relato de experiência do qual emergirá uma reflexão teórica sobre o complexo campo da EaD e suas múltiplas dimensões, mas o compartilhamento de algumas impressões, indagações, (in)compreensões e descobertas sobre uma das formas de vivenciá-la na formação de profissionais de saúde-educadores.

As trocas entre os que aprendem EaD fazendo e aqueles que se dedicam ao desvelamento da sua essência, inclusive contribuindo na construção de bases teóricas, têm sido consideradas, por nós, necessárias e bem-vindas para ajudar na superação do nível de desconhecimento e dos temores sobre as 'intencionalidades e conseqüências' da utilização dessa modalidade, ainda presentes entre os sujeitos da educação na saúde.

Conscientes dos riscos de limitar nossa leitura ao lugar que ocupamos nesse processo - a coordenação nacional do curso, no Programa de Educação a Distância da Ensp - , não nos deteremos no detalhamento da sua estrutura ou dinâmica, a não ser para expressar mais claramente o que desejamos compartilhar.

Como compreendemos essa experiência no interior das relações estimuladas pelas políticas públicas de formação de profissionais de saúde, com 
vistas à consolidação do Sistema Único de Saúde (SUS), somos remetidos ao encontro de outros atores e processos em curso no campo da formação em saúde, além daqueles circunscritos ao curso em si.

Apesar disso, ressaltamos que não falaremos como especialistas em EaD, em tecnologias educacionais, ou como apologistas das inovações tecnológicas aplicadas à educação, nos permitindo dizer que abordaremos a EaD em saúde, mas nem tanto quanto pode ser esperado, uma vez que o quanto se fala, efetivamente, de EaD não é tão simples de ser 'assegurado'.

\section{Das (nossas) imprecisões em EaD}

Existem múltiplas concepções e visões sobre o que é educação a distância ${ }^{3}$. Enfatiza-se este ou aquele 'elemento constitutivo' ou 'essencial', com exclusiva, maior ou menor densidade tecnológica, ausência absoluta ou presença eventual do professor-tutor, centralidade no ensino ou na aprendizagem. A polêmica sobre a natureza da EaD se estende, inclusive, ao próprio caráter das ações desenvolvidas sob este rótulo.

Essas ações abrangem desde processos formativos seriamente concebidos, implantados, avaliados e parcial ou totalmente mediatizados por recursos tecnológicos, até um conjunto extenso de atividades que só poderiam ser chamadas de educativas em um sentido extremamente lato e banalizado do termo, como também reconhecem Belloni (2002) e Landim (1997), referenciadas em estudiosos dessa prática educativa.Tais atividades, assim como qualquer 'instrução' acessada por meio da internet,

\footnotetext{
"incluem produtos muito diversificados, que vão desde o entretenimento cultural e educativo (documentários, por exemplo) até cursos formais, oferecidos em vários suportes e modalidades, passando por artigos à la carte, que atendem a demandas sofisticadas, como o atendimento pedagógico oferecido a pais e professores" (Belloni, 2002, p. 121).
}

Aqui, porém, foram acolhidas 'falas' sobre a EaD emitidas por profissionais de saúde e educadores que buscam colocar as 'crenças em ação'4, no contexto da recente democracia brasileira - desafiada por problemas sociais muito básicos, entre eles, o do não cumprimento do direito à saúde e à educação para todos - e não posições de defensores 'intrépidos' da modalidade a distância como solução para os dilemas envolvendo trabalho e educação.

Readmirando a vivência do Curso de Formação Pedagógica cuja concretização foi impulsionada pelas demandas do Projeto de Profissionalização dos Trabalhadores da Área de Enfermagem (Profae), estratégia do Minis- 
tério da Saúde para implantar uma política de educação profissional5, em parceria com 45 instituições de educação superior, públicas e privadas, em todo o país, concluímos que, a depender da perspectiva que se tenha sobre a função social da educação, da formação em saúde e, nelas, a contribuição da modalidade a distância, não é 'tão pouco' o que pode ser trazido para este debate, das intenções à prática, a partir dessa experiência.

\section{Uma pergunta sempre presente: de qual EaD estamos falando?}

Esta é a primeira e mais recorrente pergunta feita por aqueles que lidam com a prática educativa. Não é diferente na educação a distância, embora pelo modo como algumas experiências são divulgadas - como quase paradisíacas, isentas dos esforços conhecidos por todos os que vivenciam a construção e reconstrução intelectual, emocional, profissional, social demandadas pelo processo de educar-se e educar - , muitos sejam levados a duvidar de que seja assim.

Para nós, essa é a pergunta que norteia as escolhas, os cortes e os recortes, os 'ajustes das velas' durante a 'travessia'. Da resposta, dependem as maiores e menores 'lutas' para alcançarmos as finalidades a que servem o projeto político-pedagógico, a visão e formação do professor virtual, a concepção das mediações pedagógicas e gerenciais, as concessões e também as resistências na defesa de condições reconhecidas como indispensáveis para que tal processo seja considerado educativo, promotor de formação humana. Em nosso caso, ainda temos de expressar uma política pública construtora de melhores níveis de cidadania, entre outros compromissos 'presencialmente' assumidos até o ano de 2005, quando deveremos ultrapassar a meta de 12 mil egressos acordada inicialmente.

Apesar do nosso desejo de acertar, como bem sabemos, as práticas sociais não comportam a neutralidade, uma vez que todas expressam os interesses de grupos ou indivíduos situados em um dado contexto e a tensão das relações sociais predominantes.

Desse modo, a educação que se faz à distância das salas de aula fisicamente definidas e da 'presencialidade' de professores e alunos vem sendo objeto de análises sobre o seu uso, em razão dos impactos que sofre por parte dos determinantes econômicos, políticos, tecnológicos e ideológicos que estruturam a sociedade, dita, agora, do conhecimento.

Tais análises reconhecem, contudo, que o uso das tecnologias informatizadas integra o modo hegemônico de socialização, como assinala Belloni:

“as inovações educacionais decorrentes da utilização dos mais avançados recursos técnicos para a educação (...) constituem um fenômeno social que transcende o 
campo da educação propriamente dita, para situar-se no nível mais geral do papel da ciência e da técnica nas sociedades industriais modernas" (Belloni, 2002, p. 118).

Não faz sentido, portanto, uma leitura ingênua dos processos educativos, menos ainda a negação ou rejeição acrítica do fenômeno, o que nos leva a concordar com a assertiva "educação a distância não se lamenta, discute-se" (Pires, 2001, p. 3), à qual acrescentamos: avalia-se, estuda-se, aprende-se, pesquisa-se, escolhe-se, pratica-se.

Como parte daqueles que atuam nessa modalidade educativa, sabemos que existe um universo de concepções e práticas extremamente variado, igualmente denominado educação a distância. Em parte, isso se deve à imprecisão contida nessa forma de identificar os processos educativos não presenciais, apontada desde a década de 70.

Neste universo, podem ser encontradas pesquisas e experiências comprometidas tanto com a criação de ferramentas amigáveis (que se comunicam de maneira acolhedora com o usuário e correspondem a suas necessidades) quanto aquelas que buscam conhecer as possibilidades do ciberespaço na promoção da interatividade e as capacidades desta de gerar ou estimular a autonomia intelectual e política, a criatividade, a inclusão (social e digital), implicando no uso de tecnologias, sim.

Algumas pesquisas buscam aperfeiçoar as mediações técnicas; outras, concretizar paradigmas comunicacionais; todas são potencialmente capazes de contribuir com o enfrentamento das limitações sociais, políticas e até mesmo físicas de grupos e indivíduos. Para isso, tais iniciativas vêm criando, experimentando, avaliando, "transitando da transmissão para a interatividade, abrindo perspectivas para novos fundamentos em comunicação e educação"6 (Silva, 2003, p. 51-73), reinventando o papel do professor, dos alunos, da sala de aula, apropriando-se dos recursos tecnológicos contemporâneos em prol dos novos modos de ser dos sujeitos do processo ensinoaprendizagem.

Existem ainda outras tantas intervenções e propostas que pretendem otimizar a quantidade e qualidade da oferta e do acesso e estimular a permanência dos cidadãos em processos de educação em todos os níveis.

O mais importante a considerar diante da decisão de promover educação a distância é que, com maior ou menor densidade tecnológica, as escolhas ainda são dos educadores e educandos, como em qualquer modalidade educacional.

Contudo, assim como no ensino presencial, encontra-se em crescimento um lucrativo mercado em que a informação predomina sobre a formação, 'virtualizando' os mesmos métodos criticados como transmissores, promotores de formações cada vez mais aligeiradas, imediatistas, mediante processos voltados à comunicação de linguagens e valores reprodutores de sujeita- 
dos consumidores da superficialidade, de tecnófilos alienados, de relações sociais excludentes e individualistas, cultural e politicamente destrutivos.

A banalização do processo de aprender e educar/educar-se, presente nas mais sofisticadas formas de propaganda sobre as 'facilidades' da EaD, reforça os preconceitos e também pode servir de alerta sobre essa mercantilização, que não é exclusiva da modalidade, mas nela encontra condições de expansão muito favoráveis, em função da velocidade e 'massividade' proporcionada pelas Novas Tecnologias de Informação e Comunicação (NTIC). Mais do que nunca, é preciso saber fazer escolhas a partir das respostas às perguntas que fizermos sobre a educação que queremos, para a formação de que necessitamos, em todos os níveis.

\section{EaD na saúde pública: razões para existir}

Com base nas reflexões de Carvalho (2000), situaremos nas exigências da saúde pública contemporânea algumas razões para o enfrentamento dos desafios representados pela educação a distância na formação dos profissionais de saúde, como instrumento da educação inicial e permanente desses profissionais.

As primeiras exigências são programáticas e organizacionais. Esse autor, que também é ator da educação a distância em saúde, afirma a necessidade de reformas nessas dimensões, para superar o "paradigma de conhecimento e prática fortemente hegemonizado pelo enfoque biomédico do processo saúde-enfermidade" (Carvalho, 2000, p. 1). Neste paradigma,

\footnotetext{
“a formulação das ações é privativa da esfera técnica, espaço onde os atores profissionais desenvolvem suas práticas sempre em ambientes institucionais verticalizados e padrões laborais altamente normatizados. Nesse modelo, tanto a formação de profissionais quanto a educação da sociedade para a saúde são fortemente marcados pelo modelo instrutivista de educação (Carvalho, 2000, p. 1).
}

Destaca Carvalho que, à medida que ocorre a incorporação dos conhecimentos oriundos das ciências sociais, vai sendo constituído um novo campo das ciências da saúde, mais compreensivo e acolhedor da intersubjetividade, requalificando os marcos conceituais do trabalho em saúde, que passam do combate à doença para a promoção da vida com qualidade, de evento biológico para produção social. Isso permite que a saúde possa ser compreendida como um fenômeno complexo e o trabalho em saúde passe a representar um "campo interdisciplinar de conhecimento e intersetorial de práticas" (Carvalho, 2000, p. 2).

Em um conceito afirmativo e amplo, resultado da compreensão interdisciplinar do processo saúde-enfermidade, saúde passa a ser expressão de ca- 
pacidade e autonomia e não de um fim idealizado - a vida sem doença. Neste enfoque, o 'social' deixa de ser uma variável e passa a ser reconhecido como um determinante a ser enfrentado. Daí emergem as mudanças na visão do doente-objeto para o cidadão-sujeito e a ampliação das capacidades individuais, coletivas, comunitárias, requerendo a educação como mediação potencializadora das capacidades humanas e superando a indução normativa de hábitos e prescrições.

Em síntese, "pode-se dizer que as tendências atuais de mudança nos sistemas de saúde apontam para um novo modelo assistencial (promoção da saúde e integralidade da atenção) e para um novo desenho institucional (descentralização e participação social)", conforme Carvalho (2000, p. 2).

Em decorrência, as novas exigências se fazem também no âmbito pedagógico e "envolvem importantes alterações na demanda educacional (...) em termos da composição da clientela-alvo, da escala da oferta necessária e das competências profissionais desejadas" (Carvalho, 2000, p. 2).

A clientela - agora composta pelos novos atores da saúde, para além dos profissionais - passa a incluir os cidadãos-usuários no desenvolvimento do seu papel no controle social, o que impõe programas e estratégias educativas aplicados em 'larguíssima escala', do nível individual e local à cobertura nacional.

É necessário que tais ações ajudem os cidadãos-usuários a enfrentar problemas complexos e com baixo grau de estruturação, pensar e produzir soluções criativas (e não apenas aplicar normas), trabalhar em equipe, aprender (permanentemente), adaptar-se e responder a novas situações.

Temos utilizado algumas perguntas que podem nos ajudar a concretizar mais ainda essas razões. Precisamos promover a inclusão ampliada de participantes na educação permanente e na formação profissional em saúde? É necessária a inclusão de muitos em uma mesma oportunidade formativa, potencializando os recursos públicos e os benefícios sociais? É importante construirmos uma rede colaborativa de compartilhamento de experiências transformadoras das práticas profissionais e organizacionais dos serviços de saúde entre as regiões do Brasil? É preciso produzir conhecimento interdisciplinar e 'multicêntrico' entre projetos pedagógicos de formação profissional, de controle social, de gestão democrática de serviços e escolas, de vivências no SUS, dos impactos sociais das políticas públicas, envolvendo estudantes, docentes, profissionais, organizações sociais, entre outros?

Tais processos, em uma escala 'larguíssima', requerem novos modos de agir para se fazerem acontecer, principalmente diante da necessidade de evitar o deslocamento e o afastamento dos espaços de trabalho, e de possibilitar a participação de toda a equipe, "o que é de altíssima relevância para o campo da saúde pública", reitera Carvalho (2000, p. 3).

As novas tecnologias de informação e comunicação apresentam-se como capazes de apoiar tais processos, viabilizando propostas centradas na apren- 
dizagem, "a serviço da formação do indivíduo, profissional de saúde ou cidadão-usuário, como sujeito autônomo no aprender e no exercer ações de saúde pública" (Carvalho, 2000, p. 3).

O autor conclui que a reforma pedagógica exigida pela nova saúde pública "pode ser (...) direcionada a uma educação aberta e a distância, numa concepção que articule formação inicial e ao longo da vida, (...) estabelecendo fortes laços entre a ação educacional e a ação laboral" (Carvalho, 2000, p. 4).

Por isso,

“não pode nem deve limitar-se a suprir demandas emergenciais nem corrigir insuficiências pontuais ou regionais de educação presencial, devendo incorporarse progressivamente ao sistema regular que precisa então ser reconcebido na sua dimensão de formação inicial e enriquecido com o advento de uma educação ao longo da vida" (Carvalho, 2000, p. 3).

Carvalho reconhecia, então, que o desafio de aprender a ensinar, diante das novas exigências, incluía a formação de professores, requerendo um "processo permanente de monitoramento e estruturas de apoio docente onde possam ser desenvolvidas as dimensões técnico-didáticas, pedagógicas e tecnológicas" (Carvalho, 2000, p. 4).

\section{EaD em saúde e a política de educação para o SUS}

Particularmente em relação à formação em saúde, ainda se faz necessário discutir ampla e sistematicamente o papel da mediatização técnica - na qual os materiais multimídia participam da relação pedagógica — sem desvinculá-la das especificidades das formações profissionais, entendidas como a construção da competência humana daqueles que atuam ou atuarão no cuidar das pessoas e coletividades.

Experiências com a oferta de disciplinas a distância - on-line, off-line, semipresenciais - ou mesmo com ambientes virtuais que apóiam estudantes e professores em disciplinas presenciais mediante realização de fóruns, chats e grupos colaborativos precisam ser mais divulgadas e debatidas.

A socialização dessas práticas pode possibilitar maior conhecimento e impulsionar a coragem de experimentar as possibilidades dessa mediatização na construção das habilidades e atitudes requeridas pelo perfil profissional contido nas diretrizes curriculares nacionais dos cursos de graduação na área de saúde, por exemplo. Para isso, é indispensável que a qualidade técnica seja integrada à qualidade política.

Outro importante elemento a considerar é a recuperação dos vínculos e das relações entre os objetivos políticos e pedagógicos das formações em 
saúde. Ela tem sido o principal conteúdo do movimento de mudanças que vêm ocorrendo há mais de vinte anos em torno do ensino superior em saúde, referenciado no conceito de saúde como qualidade de vida, em busca da integração dos processos formadores com os interesses sociais, e da consolidação de um sistema de saúde capaz de contribuir para que esta seja um direito de todos.

O Ministério da Saúde tem promovido estratégias que impulsionem as diversas experiências institucionais de mudança e que reiterem a perspectiva da integralidade do cuidado, a centralidade do trabalho em saúde como eixo organizador da formação profissional, o SUS como locus e alvo maior da formação.

A estratégia denominada Aprender SUS representa a política proposta pelo Ministério da Saúde para a mudança na formação dos profissionais de saúde no âmbito do ensino de graduação. De acordo com tal política, a formação para a área da saúde deve ter como objetivo a "transformação das práticas profissionais e da própria organização do trabalho e estruturar-se a partir da problematização do processo de trabalho e sua capacidade de dar acolhimento e cuidado às várias dimensões e necessidades em saúde das pessoas, dos coletivos e das populações" (MS, 2004a, p. 4).

As vivências e os estágios nas realidades do SUS - através do projeto Versus - fazem parte da estratégia do Ministério da Saúde e do movimento estudantil da área para aproximar os estudantes universitários dos desafios inerentes à implantação do SUS em todo o território nacional. Uma vivência em que os profissionais em formação problematizam a organização dos serviços de saúde nas diferentes regiões do país.

Essas estratégias complementam-se, na medida em que estão voltadas para a graduação e seus atores docentes, gestores e discentes, na interlocução com gestores e usuários do sistema de saúde.

Entendemos que as experiências em educação a distância, sejam complementares ou parte integrante dos currículos de graduação ou pós-graduação, não podem ignorar os processos, as diretrizes, os movimentos políticos que promovem a política de educação para o SUS, o que implica de forma especial as instituições promotoras dessa modalidade.

Se desejamos, de fato, que os processos formadores sejam contextualizados, não podemos desconsiderar os limites e as possibilidades contemporâneas para a superação das distâncias culturais, sociais, técnico-científicas, tecnológicas, geográficas e físicas presentes na sociedade em que vivemos, oferecidas pelas múltiplas formas de educar/educar-se que passaram a existir, além da modalidade presencial.

Os educadores em saúde precisam ampliar e participar dessa discussão a ponto de poderem considerar a educação a distância como um fenômeno que faz "parte de um processo de inovação educacional mais amplo que é a 
integração das novas tecnologias de informação e comunicação nos processos educacionais" (Belloni, 2002, p. 123).

Não é preciso, contudo, que os educadores e estudantes 'abram mão' da clareza de que a modalidade não se justifica por si mesma, não é um 'imperativo categórico' para todo e qualquer momento, objetivo pedagógico, sujeito, tipo de aprendizagem, interação, experiência que se queira promover ou vivenciar. Tal escolha implica a avaliação crítica dos benefícios para a aprendizagem, o que supõe a reorientação da oferta comumente encontrada, de forma 'avulsa' e descolada de um projeto ou de uma política que a norteie.

As ofertas na modalidade a distância são parte da realidade abordada anteriormente, merecendo o mesmo cuidado quanto a sua qualidade e legalidade. No país, ela se configura como educação semipresencial, requerendo exames presenciais, de responsabilidade da instituição credenciada, segundo procedimentos e critérios definidos no projeto autorizado.

A maior parte das iniciativas em EaD dirigidas aos profissionais de saúde apresenta-se como cursos de pós-graduação lato sensu - atualização, aperfeiçoamento, especialização — , a exemplo de cursos voltados para a sistematização da assistência de enfermagem em áreas especializadas e para os procedimentos médicos e odontológicos de diagnóstico e tratamento, apoiados em diferentes suportes e mídias.

Em universidades públicas e privadas, são oferecidos, ainda, cursos de capacitação de docentes em ciências da saúde, para realizar o planejamento e coordenar o desenvolvimento de cursos a distância, com aplicações nas áreas básica e clínica. Outros cursos têm como objetivo motivar enfermeiros(as) para a utilização do ambiente virtual como instrumento de aprendizagem, visando à capacitação de educadores para fazerem uso dos recursos da educação on-line como apoio à educação presencial.

Se não é obrigatório cairmos no canto das "sereias do ensino eletrônico", como afirmam Blikstein e Zuffo (2003, p. 27), tampouco precisamos desistir das suas potencialidades por medo da sedução ou por desconhecimento, uma vez que a nossa condição de seres criadores, em constante busca pelo atendimento das necessidades que reconhecemos como tais, é o que possibilita a existência e o uso de tecnologias ao longo da história humana.

Sem medo de dizermos o que o bom senso e a problematização da realidade nos ensinaram ao longo da nossa história de vida e reconhecendo que não estamos diante de 'uma verdadeira e unificante revolução', mas, também, que não se trata apenas de "mais uma unanimidade à moda de Nelson Rodrigues", como nos provocam Blikstein e Zuffo (2003, p. 24), relembramos o título do texto: "nem tanto, nem tão pouco", certamente. 


\section{As 'crenças em ação'}

Se não nos cremos envolvidos pelo "canto das sereias eletrônicas" ou pela mercantilização da educação e se concordamos com Carvalho (2000, p. 4) que "a escolha tecnológica deve subordinar-se à escolha pedagógica no sentido de que o centro do processo é a facilitação da auto-aprendizagem e não a ostentação tecnológica", devemos reconhecer que a conquista de direitos sociais básicos pode integrar o elenco de razões que mobilizam a ação educativa por meio da EaD.

Em nossa experiência, essa consciência aumentou a responsabilidade das escolhas em termos políticos e pedagógicos, uma vez que o Curso de Formação Pedagógica em Educação Profissional na Área de Saúde: Enfermagem foi implantado em todas as regiões e em todos os estados do país, como mencionado anteriormente.

Por essa proposta ser fruto de uma luta histórica pela profissionalização dos trabalhadores da enfermagem, principalmente dos atendentes; por representar o necessário investimento na formação permanente dos formadores, com ênfase na dimensão pedagógica e na ação docente; e por ter sido consubstanciada como proposta político-institucional do Ministério da Saúde e concebida no âmbito do programa de EaD da Ensp, ficamos atentos ao alerta sobre as experiências de educação a distância no Brasil.

Segundo Belloni, podem ser observadas, nessas experiências, “algumas características estruturais recorrentes: as políticas públicas do setor têm um caráter tecnocrático, autoritário e centralizador que as destina necessariamente a resultados medíocres, se não ao fracasso" (Belloni, 2002, p. 124).

Como forma de demonstrar a nossa crença na importância da co-responsabilidade e participação dos coordenadores e tutores na 'vigilância' das condições políticas e pedagógicas concretamente vivenciadas no curso, que possam indicar a presença das características citadas acima, este 'alerta' foi sinalizado no Livro do tutor (MS, 2003, p. 38). Em alguns momentos, a mobilização desses atores e de suas organizações profissionais fortaleceu os gestores e a continuidade das ações.

Belloni identifica, ainda, como dificuldades para pesquisar sobre os aspectos propriamente técnicos ou pedagógicos das experiências, as determinações econômicas e políticas e o perfil tecnocrático das propostas, que, “às vezes, válidas do ponto de vista puramente técnico, não levam em consideração as condições (sociais e políticas, micropolíticas) de realização, o 'chão social' sobre o qual os projetos são construídos" (Belloni, 2002, p. 125).

Devido à natureza da proposta - uma ação educativa voltada para a formação de formadores em saúde, no âmbito da educação profissional de nível técnico - redobramos, no curso, a atenção em termos político-gerenciais e pedagógicos, uma vez que este tem sido um dos espaços em que a educação a distância vem sendo amplamente utilizada, e não menos criticada. 
As críticas aos processos de formação de formadores a distância enfocam questões de cunho pedagógico e político-social, tais como: ausência de momentos presenciais, aligeiramento do processo de formação, venda de serviços educacionais a baixo custo, reforço à precarização das relações de trabalho, formação pragmática a partir da demanda do cliente, ameaça à autonomia universitária, entre outros argumentos (Leher, 2001, p. 5).

Entendendo a EaD como "serviço público e estratégia de ensino que pode e deve estar inserida nas linhas de força que permeiam o debate em torno dos mais graves problemas educacionais brasileiros" (Alves, 2001, p. 46) - entre os quais se encontra a educação profissional inicial e permanente em saúde, abrangendo a formação dos formadores em qualidade e quantidade capazes de atender as necessidades do SUS - , foram construídas as principais estratégias que estruturam o curso, ainda em andamento, fortalecendo a posição vigilante acima mencionada.

Essa experiência de formação, ação de muitos, que envolve desde a elaboração do projeto, produção de material didático, negociação e estabelecimento de convênios com as universidades parceiras, até a gestão acadêmica e a certificação dos alunos, centrou na estruturação dos NAD (Núcleos de Apoio Docente) e das turmas a serem atendidas, na formação inicial e continuada dos tutores, e no constante 'cuidado' de acompanhamento das ações — viabilizador de medidas de aperfeiçoamento de caráter administrativo e político-pedagógico da proposta em desenvolvimento - as estratégias de sustentação de desafios múltiplos: a realização de um curso destinado simultaneamente a um grande número de alunos, na perspectiva crítica da educação e da saúde, em realidades diversas, mediante modalidade a distância.

No desejo de conhecermos os limites e as possibilidades desse processo educativo que, prescindindo da contigüidade espacial e temporal dos sujeitos, oferece suporte de alguns recursos tecnológicos, de mediação tutorial, de momentos presenciais, de trabalho em grupo e de formas alternativas de avaliação do aluno na perspectiva da inclusão, criamos uma infra-estrutura de gerenciamento das informações para a coordenação do curso na Ensp. Paralelo a isto, em uma espécie de acompanhamento a distância da educação a distância, zela-se especialmente pela atuação do Sistema de Acompanhamento Pedagógico (SAP) como instância formadora e busca-se desenvolver ações avaliativas que possam captar as percepções dos atores envolvidos na proposta - os tutores e alunos, em especial. Estes foram convidados a participar das oficinas de acompanhamento e avaliação das turmas iniciais do curso, orientando, por exemplo, a revisão da segunda edição do conjunto didático. Com eles, foram realizadas pesquisas para analisar causas de evasão e avaliar aspectos estruturais da proposta. Esses estudos permitiram uma maior aproximação do perfil dos sujeitos do curso: docentes-enfer- 
meiros com múltiplos vínculos de trabalho, muitas vezes em condições precarizadas, com pouca disponibilidade de tempo para estudo, com lacunas de conhecimento das ciências sociais em sua formação universitária e com dificuldade de acesso à cultura digital.

O SAP, instituído em face da constatação de que os processos formativos voltados à qualidade social requerem tempo e investimento, vem atuando em uma perspectiva de construção coletiva, pautada no diálogo, com o objetivo de, respeitada a autonomia dos NAD, fortalecer as ações pedagógicas, por meio de diferentes estratégias, com funções diagnóstica, formativa e socializadora. Entre tais estratégias, assinale-se a análise qualitativa dos dados da gestão acadêmica e dos relatórios dos NAD, os contatos sistemáticos por correio eletrônico, as visitas aos NAD, a realização de oficinas regionais, a disponibilização de materiais na rede e a elaboração de relatórios de tendências, como subsídio a reorientações no processo.

É evidente que, ao lado dos resultados quantitativos da experiência e de depoimentos como o de defesa da incorporação de um 'fazer educativo' inovador em conteúdo e metodologia, nos cursos de graduação, como fruto da experiência construída no curso (na avaliação de tutores), de uma maior compreensão das relações político-pedagógicas na saúde e na educação (expressa em falas de enfermeiros-docentes a respeito de mudanças na prática do serviço e da sala de aula), reafirmamos nossas crenças nas 'virtualidades' da educação a distância, mas não distante.

Contudo, é necessário conhecê-la mais e mais em termos políticos, pedagógicos e gerenciais e, em especial na saúde, é preciso ajudá-la a expressar e concretizar intenções educativas críticas, recontextualizadas no movimento histórico por mudanças nos campos dos saberes e práticas.

Em busca do maior conhecimento possível sobre o 'chão' em que está sendo assentado o curso, descobrimos que, embora a educação a distância no Brasil tenha completado, em 2004, um século de existência (Nidecker, 2004), tendo feito, nesse período, um percurso desde o ensino por correspondência até a Universidade Virtual (Vianney, Torres e Silva, 2003), a maioria expressiva das instituições parceiras - universidades públicas federais e estaduais e um pequeno número de instituições privadas — não possuía experiência em nenhum tipo de educação a distância na área de saúde, incluindo a enfermagem. No entanto, em algumas dessas instituições, 'identificamos' a existência de setores ou núcleos de EaD localizados em outras unidades, sem que houvesse qualquer ação conjunta.

Apesar da divulgação crescente da produção sobre o tema EaD, além do esforço da Ensp com seu pioneiro Programa de Educação a Distância (Proead), as 'escolas da saúde' continuam, praticamente, a ignorar a modalidade e, principalmente, as abordagens que a reconhecem como uma prática social, com vantagens e desvantagens. 
Se os temores e desconfianças já eram grandes — vemos, freqüentemente, em revistas e jornais de grande circulação a EaD apresentada como 'a nova onda da educação', 'o sistema que mais lucrou com os avanços tecnológicos', 'um mercado muito atraente para as grandes corporações empresariais' - , não podemos deixar de compreender as reações que ainda subsistem no campo da saúde, entre educadores e alunos, a respeito dessa maneira de promover educação, a ponto de provocarem moção de repúdio a cursos de graduação a distância na área de saúde, especificamente na enfermagem, como foi oficiado ao MEC no recente Seminário da Associação Brasileira de Enfermagem (ABEn) (MEC, 2004).

Sem dúvida, os temores residem, também, no desconhecimento dos muitos modos de aprender-ensinar que envolvem o uso de tecnologias nos processos educativos, inclusive as de comunicação e informação altamente desenvolvidas e diversificadas, associando-se à falta de maior contato direto com o professor-tutor, aos novos papéis e às novas atitudes requeridos dos professores e alunos no contexto da EaD e ao 'tratamento especial' a ser dado aos conteúdos teóricos e práticos, em função do contexto de separação espaço-temporal.

Entendemos que todas essas questões têm de ser alvo de debates, estudos e produções nas iniciativas do setor saúde, especialmente quando elas pretendem desenvolver, junto a seus formadores, uma formação pedagógica voltada à ação docente autônoma e significativa e, com ela, contribuir para a inclusão educacional e social dos trabalhadores de nível técnico.

Com certeza, os milhares de alunos e centenas de tutores da experiência de formação pedagógica promovida pela política pública do Ministério de Saúde, no âmbito do Profae, poderão ajudar a refletir sobre 'os tantos' e 'os poucos' desse modo de assumir a marcha da educação a distância, no sentido de que a dor, a justiça e o futuro não nos sejam indiferentes, como assinala a canção. 


\section{Notas}

1 Coordenadora nacional do Curso de Formação Pedagógica em Educação Profissional na Área de Saúde: Enfermagem, da Escola Nacional de Saúde Pública Sergio Arouca, Fiocruz, e Secretaria de Gestão do Trabalho e da Educação na Saúde, Ministério da Saúde. Mestre em Educação pela UFRJ. <miltatorrez@ead.fiocruz.br>

2 Desenganado.

3 Para apoiar a compreensão das manifestações contemporâneas da EaD, é necessária a leitura da construção histórica das suas definições e conceituações e de como estas sofrem os impactos dos paradigmas econômicos. Sugerimos Belloni (1999), Lobo Neto (2001) e Landim (1997).

4 Conforme entrevista do brasilianista britânico Kenneth Maxwel, em que expõe as 'ambigüidades' da democracia brasileira a Sergio Vilas Boas (2004).

5 Esse curso foi concebido como estratégia de sustentabilidade para a formação de auxiliares de enfermagem pelo Profae, em parceria com a Escola Nacional de Saúde Pública Sergio Arouca, Fundação Oswaldo Cruz, com a meta de formar 12 mil enfermeiros especialistas em educação profissional na área de Saúde-Enfermagem.

6 Discute-se o conceito complexo de interatividade, apresentado como "fundamento essencial da cibercultura e do digital, tomado para além do sentido meramente mercadológico, bastante disseminado", em que assume "o sentido de 'argumento de vendas', que mascara, fabrica adesão, produz opinião pública a partir do objeto-publicidade (p. ex. tênis interativo (...) game interativo, etc.)" (Silva, 2003, p. 53). Neste conceito complexo, precisam ser garantidos pelo menos três aspectos essenciais: participação colaborativa, bidirecionalidade e dialógica e conexão em teias abertas. 


\section{Referências}

ALVES, Amélia Maria de A. 2001. Educação a distância e educação continuada. In: LOBO NETO, Francisco J. S. (org.). Educação a distância: referências e trajetórias. Rio de Janeiro: Associação Brasileira de Tecnologia Educacional (ABT), p. 46-52.

BELLONI, Maria Luiza. 1999. Educação a distância. Campinas: Autores Associados. . 2002. Ensaio sobre a educação a distância no Brasil. Educação \& Sociedade, v. 23, n. 78, p. 117-142.

BLIKSTEIN, Paulo; ZUFFO, Marcelo K. 2003. As sereias do ensino eletrônico. In: SILVA, Marco (org.). Educação online. São Paulo: Edições Loyola, p. 23-38.

CARVALHO, Antonio Ivo. 2000. A educação a distância e a nova saúde pública. Rio de Janeiro: Escola Nacional de Saúde Pública Sergio Arouca, Fundação Oswaldo Cruz, Ministério da Saúde. (Mimeo). .2004. Rede Escolas de Governo: estratégia inovadora para a consolidação do SUS. Rio de Janeiro: Escola Nacional de Saúde Pública Sergio Arouca, Fundação Oswaldo Cruz, Ministério da Saúde. (Mimeo).

LANDIM, Cláudia Maria das M. P. F. 1997. Educação a distância: algumas considerações. Rio de Janeiro: [s.n.].

LEHER, Roberto. 2001.O foco da distância. Advir, n. 14, p. 5-9.

LOBO NETO, Francisco J. S. (org.). 2001. Educação a distância: referências e trajetórias. Rio de Janeiro: Associação Brasileira de Tecnologia Educacional (ABT).

MEC (Ministério da Educação). 2004. Oficio n. 4.231. Regulamentação da oferta de cursos superiores a distância. Resposta
Moção de Repúdio. Brasília: Departamento do Ensino Superior, Secretaria da Educação Superior, Ministério da Educação.

MS (Ministério da Saúde). 2003. Formação pedagógica em educação profissional na área de saúde: Enfermagem. Livro do tutor. Brasília: Projeto de Profissionalização dos Trabalhadores da Área de Enfermagem (Profae), Secretaria de Políticas de Saúde, Ministério da Saúde. .2004a. Aprender SUS: o SUS e os cursos de graduação da área da saúde. Brasília: Departamento de Gestão da Educação em Saúde, Secretaria de Gestão do Trabalho e da Educação na Saúde, Ministério da Saúde.

2004b. Projeto Versus/Brasil: vivências e estágios nas realidades do Sistema Único de Saúde. Brasília: Departamento de Gestão da Educação em Saúde, Secretaria de Gestão do Trabalho e da Educação na Saúde, Ministério da Saúde.

NIDECKER, Fernanda. 2004. Educação a distância. Jornal do Brasil, Rio de Janeiro, 25 set. Idéias, p. 1 .

PIRES, Hindenburgo Francisco. 2001. Educação a distância não se lamenta, discute-se. Advir, n. 14, p. 3.

SILVA, Marco. 2003. Criar e professorar um curso online: relato de experiência. In: SILVA, Marco (org.). Educação online. São Paulo: Edições Loyola, p. 51-73.

VIANNEY, João; TORRES, Patrícia L.; SILVA, Elizabeth F. da. 2003. A universidade virtual no Brasil: o ensino superior a distância no país. Tubarão: Unisul.

VILLAS BOAS, Sergio. 2004. Crenças em ação. Cult, v. 85, n. 7, p. 55-57. 